\title{
Токсичность молекул и мицелл стабилизатора наночастич серебра в исследовании их действия на клетки эндотелия
}

\author{
Каба С.И., Егорова Е.М.
}

Федеральное государственное бюджетное научное учреждение

«Научно-исследовательский институт общей патологии и патофизиологии».

125315, Москва, ул. Балтийская, д. 8

Актуальность. Определяли цитотоксичность растворов анионного поверхностно-активного вещества (ПАВ) аэрозоля-ОТ (AОT), используемого в качестве стабилизатора наночастиц серебра (НЧС), в экспериментах на клетках эндотелия.

Цель работы: выявить отдельные вклады мономеров и мичелл стабилизатора в токсическое действие растворов наночастиц.

Методы. Цитотоксичность оценивали с помощью МТT-теста по изменениям жизнеспособности эндотелиальных клеток линии ЕА. .у926 после 24-часовой инкубации с растворами АОТ. При этом учитывали влияние ионной силы на критическую концентрацию мицеллообразования (ККМ) и соответственно, на соотношение мономеров и мицелл АОТ в растворе НЧС.

Результаты. Получены скорректированные данные по читотоксичности АОТ в составе раствора НЧС, которые позволили оценить отдельные вклады мономеров и мицелл АОТ в общий эффект препарата наносеребра.

Выводы. Предложенный нами методологический подход даёт возможность более точно оченивать токсичность водных растворов заряженных ПАВ, а также продвинуться в понимании механизма их действия на живые организмы как в качестве стабилизаторов наночастии, так и в качестве антивирусных или антибактериальных средств для наружного применения в медицинской практике.

Ключевые слова: цитотоксичность поверхностно-активных веществ; аэрозоль-ОТ; наночастицы серебра; критическая концентрачия мичеллообразования.

Для цитирования: Каба С.И., Егорова Е.М. Токсичность молекул и мицелл стабилизатора наночастиц серебра в исследовании их действия на клетки эндотелия. Патогенез. 2019; 17(4): 63-68

DOI: $10.25557 / 2310-0435.2019 .04 .63-68$

Для корреспонденции: Каба Саид Ибрагимович, e-mail: said.kaba@gmail.com

Финансирование. Исследование не имеет спонсорской поддержки.

Конфликт интересов. Авторы заявляют об отсутствии конфликта интересов.

Поступила: 19.09.2019

\section{Toxicity of stabilizer molecules and micelles in studying the effect of silver nanoparticles on endothelial cells}

Kaba S.I., Egorova E.M.

Institute of General Pathology and Pathophysiology,

Baltijskaya Str. 8, Moscow 125315, Russian Federation

Background. Cytotoxicity of anionic surfactant aerosol-OT (AOT) used as a stabilizer of silver nanoparticles (AgNPs) was studied on endothelial cells.

The aim: to determine individual contributions of AOT monomers and micelles to the toxic effect of AgNPs solution.

Methods. Cytotoxicity was evaluated using the MTT assay by changes in viability of EA.hy926 cells after 24-h incubation with AOT solutions. Experiments were performed with regard for the influence of ionic strength on the micelle critical concentration (and thus, on monomer-micelle ratio) of AOT in the AgNPs solution.

Results. The study provided corrected data on cytotoxicity of the AOT present in the AgNPs solution, which allowed estimating individual contributions of monomers and micelles to the total toxic effect of nanoparticle solution.

Conclusions. The proposed methodological approach provides more accurate estimation of charged surfactant toxicity and a better insight into the mechanism of their toxic effect on living organisms in using the charged surfactants either as nanoparticle stabilizers or as antiviral and antibacterial agents for external use in medical practice.

Key words: cytotoxicity of surfactants; aerosol-OT; silver nanoparticles; critical micelle concentration.

For citation: Kaba S.I., Egorova E.M. [Toxicity of stabilizer molecules and micelles in studying the effect of silver nanoparticles on endothelial cells]. Patogenez. [Pathogenesis]. 2017; 17(4): 63-68 (in Russian)

DOI: $10.25557 / 2310-0435.2019 .04 .63-68$

For correspondence: Kaba Said Ibragimovich, e-mail: said.kaba@gmail.com.

Funding. The study had no sponsorship.

Conflict of interest. The authors declare no conflict of interest.

Received: 19.09.2019 


\section{Введение}

Как было показано недавно в ряде исследований на клетках in vitro [1-7], в том числе в наших экспериментах на культурах нормальных и злокачественных клеток [5-7], в токсичность водных растворов наночастиц серебра, стабилизированных поверхностно-активными веществами (ПАВ), существенный вклад может вносить стабилизатор. Отсюда следовало, что в подобных экспериментах для выяснения собственного эффекта наночастиц необходим параллельный контроль токсичности водных растворов стабилизатора с той же концентрацией, что и в растворах наночастиц. Как уже отмечалось нами ранее [8], при проведении таких контрольных измерений обычно считалось достаточным сравнить действие раствора наночастиц с действием раствора стабилизатора в дистиллированной воде.

Между тем, при проведении исследований токсичности наночастиц серебра (НЧС), стабилизированных анионным ПАВ (АОТ), на клетках Jurkat, мы привлекли имеющиеся в литературе данные о связи между цитотоксичностью заряженных ПАВ и их критической концентрацией мицеллообразования (KКМ) [9], которая определяет соотношение концентраций двух разных форм существования ПАВ в растворе мономеров и мицелл. Поскольку хорошо известно, что ККМ заряженных ПАВ зависит от ионной силы раствора [10], для корректного контроля токсичности АОТ в растворе НЧС необходимо было определить токсичность водного раствора АОТ не только той же концентрации, но и с той же ионной силой, что и в растворе НЧС. Для этого мы измеряли ионную силу раствора НЧС и сравнивали токсичность раствора АОТ в дистиллированной воде и в модельном растворе нитрата калия с той же ионной силой, что и в растворе НЧС. В результате нами было показано, что в растворе с более высокой ионной силой токсичность АОТ существенно превышает таковую для дистиллированной воды; это означало, что «контроль токсичности заряженного ПАВ следует проводить с учетом различия его критической концентрации мицеллообразования в воде и в растворе наночастиц» [8].

Используя эти данные, а также найденные нами значения ККМ АОТ в воде и растворе нитрата калия, мы разработали методику определения отдельных вкладов в цитотоксичность мономеров и мицелл АОТ. Были получены зависимости вклада каждой из двух форм АОТ от его общей концентрации в растворе; характер этих зависимостей позволил предположить, что мицеллы более токсичны, чем мономеры, что может указывать на разный механизм взаимодействия этих форм ПАВ с биологической клеткой. Предложенная методика и результаты, полученные на клетках Jurkat, подробно описаны в нашей недавней публикации [11]. Разработанная нами общая стратегия разделения вкладов разных форм основана на известных свойствах водных растворов ПАВ и не зависит от особенностей исследуемого биологического объекта, поэтому были основания полагать, что различия в токсичности мономеров и мицелл ПАВ можно выявить таким же путем на клетках другого типа. Однако, характер изменений вкладов этих двух форм с концентрацией ПАВ может зависеть от типа клеток и потому для других клеток может отличаться от наблюдаемого на клетках Jurkat, что будет указывать на вероятные отличия в механизме токсического действия мономеров и мицелл.

Цель настоящей работы - определить вклады мономеров и мицелл в цитотоксичность АОТ, используемого в качестве стабилизатора НЧС, по отношению к клеткам эндотелия. Культура клеток эндотелия (линия ЕА.hy926) была выбрана вследствие двух её существенных отличий от клеток Т-лимфобластной лейкемии человека, суспензионного типа, каковыми являются клетки Jurkat. Во-первых, линия ЕА.hy926 - это нормальные, а не злокачественные клетки и, во-вторых, это клетки адгезионного, а не суспензионного типа, что может существенно сказываться на чувствительности клеток к токсическому действию ПАВ; такой вывод был нами сделан ранее при сравнении действия НЧС, стабилизированных АОТ, на злокачественные клетки адгезионного и суспензионного типа - соответственно, HELa и U937 [5]. В исследовании на клетках эндотелия использовались растворы АОТ двух концентраций. Один раствор был той же концентрации (3 ммоль/л), в которой этот стабилизатор вводили при синтезе НЧС; как было нами показано ранее [11], при этой концентрации АОТ как сами наночастицы в диапазоне концентраций 1-7 мкг Ag/мл, так и контрольный водный раствор АОТ при соответствующих разведениях демонстрировали заметную токсичность для клеток Jurkat. Для определения вклада мономеров использовали также другой раствор АОТ с концентрацией, равной его ККМ в растворе НЧС (1,7 ммоль/л). Учитывая необходимость коррекции контроля токсичности стабилизатора на изменение его ККМ в растворе НЧС по сравнению с дистиллированной водой [8], в обоих случаях растворы АОТ готовили в растворе $\mathrm{KNO}_{3}$ с концентрацией 8 ммоль/л, т.е. с той же ионной силой, что и найденная ранее для раствора НЧС, стабилизированных 3 ммоль/л АОТ. Токсичность растворов АОТ оценивали по изменениям жизнеспособности клеток эндотелия с помощью МТТ-теста. Здесь мы приводим основные результаты экспериментов на клетках и найденные из них зависимости вкладов мономеров и мицелл от общей концентрации АОТ в цитотоксическое действие растворов АОТ и НЧС.

\section{Материалы и методы исследования}

Приготовление растворов АОТ. Исследовали: (1) 3 ммоль/л раствор АОТ (бис(2-этилгексил)сульфосукцината натрия, 96\%, «Merck», Германия), ко- 
торый служил в качестве контрольного при инкубации клеток с растворами НЧС, синтезированных в водном растворе по недавно разработанной процедуре [11] с 3 ммоль/л АОТ в качестве стабилизатора; и (2) раствор АОТ с концентрацией 1,7 ммоль/л, равной его ККМ в растворе НЧС. Готовили растворы АОТ в 8 ммоль/л растворе $\mathrm{KNO}_{3}$ (х.ч., «Реахим», Россия); использовали дистиллированную воду, как и при синтезе НЧС.

Определение KКМ для AOT в растворе $K N O_{3}$. Для определения ККМ проводили измерения электропроводности на кондуктометре НI 8733 («Hanna Instruments», США). Значение ККМ находили из зависимостей электропроводности от концентрации АОТ, вводимого из концентрированного (20 ммоль/л) раствора, в раствор нитрата калия (8 ммоль/л). Методика измерения ККМ и обоснование выбора нитрата калия для приготовления модельного раствора с целью определения ККМ АОТ в растворе НЧС даны в наших предыдущих публикациях [8, 11]. Нужную концентрацию раствора $\mathrm{KNO}_{3}$ находили из условия равенства электропроводностей растворов НЧС и $\mathrm{KNO}_{3}$. Электропроводность раствора НЧС с концентрацией AOT 3 мМ находили при измерениях их дзета-потенциала на приборе «ZetaPALS» («Brookhaven Instruments», США). Затем готовили раствор $\mathrm{KNO}_{3}$ с концентрацией, при которой его электропроводность была равна электропроводности раствора НЧС. Для НЧС с 3 ммоль/л АОТ концентрация $\mathrm{KNO}_{3}$ была равна 8 ммоль/л. Для АОТ в 8 ммоль/л $\mathrm{KNO}_{3} \mathrm{KKM}_{\text {была }}$ найдена равной 1,7 ммоль/л.

Инкубация клеток с растворами АОT и MTT-тест. Клетки Еa.hy926 (эндотелиоциты пупочной вены человека) получены из American Type Culture Collection (АТСС, США). Субкультивирование проводили в инкубаторе «New Brunswick Galaxy 48 R» («Eppendorf», Германия) при $37^{\circ} \mathrm{C}$ в увлажнённой атмосфере с $5 \%$ углекислого газа. Для культивирования клеток EA.hy926 использовали среду DMEM с добавлением $10 \%$ эмбриональной бычьей сыворотки, 2 ммоль/л глутамина, смесей питательных компонентов НАТ и NEAA в соответствии с методическими указаниями поставщика, а также 50 мкг/мл гентамицина (все компоненты - производства «Thermo Fisher Scientific», США). Пассирование клеток проводили 2 раза в неделю. Концентрацию суспензии и жизнеспособность клеток определяли методом исключения витального красителя (трипанового синего) путём подсчёта в автоматическом счётчике клеток «Countess» («Thermo Fisher Scientific») в соответствии с инструкцией к прибору. Для эксперимента использовали клетки с жизнеспособностью не менее $95 \%$.

Инкубацию клеток с растворами АОТ проводили в 96-луночных микропланшетах. В лунки планшета вносили по 200 мкл суспензии клеток с концентрацией $5 \cdot 10^{4}$ кл./мл, затем инкубировали перед экспериментом 24 ч. Затем в лунки вносили исследуемые растворы АОТ в тех же разведениях, в которых в экспериментах с наночастицами вносили растворы НЧС с концентрацией 1 ммоль/л (108 мкг/мл). Эти разведения: $108 ; 54 ; 36 ; 27 ; 21,6 ; 18 ; 15,4$, которые соответствуют диапазону концентраций наночастиц 1-7 мкг/ мл и далее обозначены как стандартные. В качестве отрицательного контроля использовали дистиллированную воду и 8 ммоль/л раствор $\mathrm{KNO}_{3}$. Клетки инкубировали 24 ч.

После инкубации клетки однократно отмывали в фосфатно-солевом буфере (pH 7,4), затем к ним вносили свежую культуральную среду и раствор МТТ до концентрации 500 мкг/мл и до объёма 200 мкл. Через 4 ч инкубации с МТТ из лунок аккуратно отбирали среду, вносили по 100 мкл диметилсульфоксида и оставляли планшеты на 20-30 мин в темноте при комнатной температуре. Оптическую плотность полученного раствора формазана в лунках измеряли на фотометре «Chameleon V» («Hidex», Финляндия) при 544 нм. Жизнеспособность клеток вычисляли как долю оптической плотности испытуемых клеток от оптической плотности контрольных клеток (инкубированных с дистиллированной водой), выраженную в процентах.

\section{Результаты и обсуждение}

Результаты измерений жизнеспособности клеток ЕА.hy926 после инкубации с растворами АОТ в 8 ммоль/л $\mathrm{KNO}_{3}$ при концентрациях AOT 3 и 1,7 ммоль/л показаны на рис. 1. Данные, полученные при концентрации АОТ 3 ммоль/л, показывают реакцию клеток на введение контрольного раствора АОТ, используемого в экспериментах с НЧС с 3 ммоль/л АОТ, после коррекции на изменение ККМ АОТ в растворе НЧС по сравнению с его ККМ в воде; необходимость такой коррекции была продемонстрирована ранее на клетках Jurkat [8]. Определение КKM для АОТ в 8 ммоль/л $\mathrm{KNO}_{3}$ дает значение 1,7 ммоль/л. Поскольку значение ККМ соответствует концентрации мономеров в растворе ПАВ [10], отсюда следует, что в растворе с концентрацией АОТ 1,7 ммоль/л присутствуют только мономеры, тогда как в растворе с концентрацией АОТ 3 ммоль/л присутствуют как мономеры, так и мицеллы, последние в концентрации $3-1,7=1,3$ (ммоль/л). Таким образом, инкубация клеток с 1,7 ммоль/л раствором АОТ позволяет вывить вклад только мономеров, а инкубация их с 3 ммоль/л раствором АОТ - показывает общий токсический эффект мономеров и мицелл.

Токсичность растворов АОТ определяется количественно как разность жизнеспособности в контроле $(\mathrm{V}=100 \%)$ и при данном разведении раствора AOT $\left(\mathrm{V}_{\mathrm{n}}\right)$, где $\mathrm{n}$ (мкг/мл) соответствует разведению раствора НЧС. Для примера на рис. 1 показаны: (1) определение вклада мономеров из данных для 1,7 ммоль/л АОТ при $n=3$ мкг/мл $\left(\Delta \mathrm{V}_{3}\right)$; и (2) общей токсичности 3 ммоль/л раствора АОТ при $n=5$ мкг/мл 
$\left(\Delta \mathrm{V}_{5}\right)$ (в обоих случаях значение $\left.p<0,05\right)$. Последняя равна сумме вкладов мономеров и мицелл, поэтому, вычитая из общей токсичности 3 ммоль/л АОТ эффект мономеров, получаем вклад мицелл. Для обоих растворов АОТ его концентрации АОТ в клеточной среде соответствовали разведениям раствора НЧС до концентраций наночастиц, указанных на оси абсцисс. При этом контрольные измерения демонстрируют полное отсутствие токсичности 8 ммоль/л раствора $\mathrm{KNO}_{3}$.

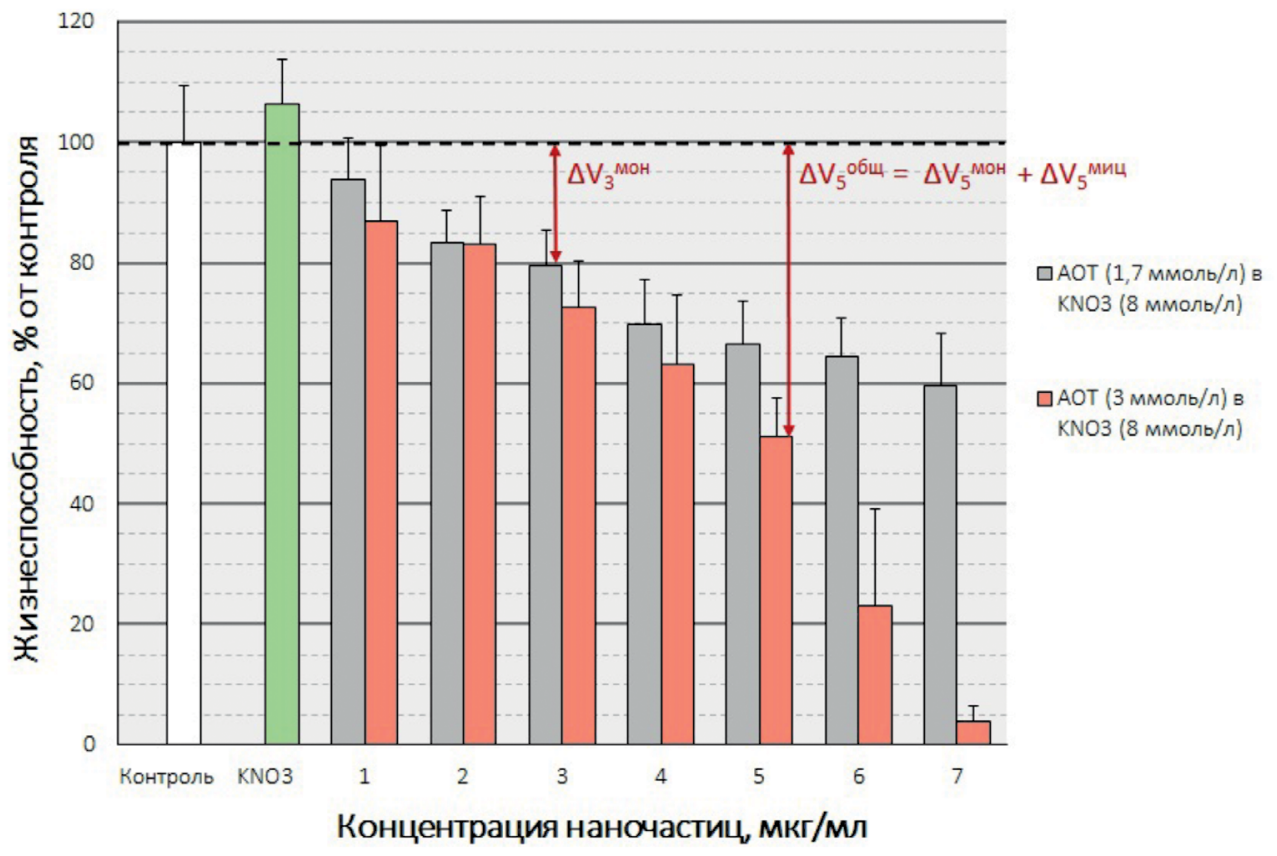

Рис. 1. Результаты определения действия растворов АОТ с концентрацией 1,7 ммоль / л и 3 ммоль/л на жизнеспособность клеток ЕА.һу926 с помощью МТТ-теста. Инкубация 24 часа. По оси абцисс цифры 1-7 - стандартные разведения (см. методы). Данные представлены как средние от 6 измерений с указанием стандартных отклонений. Отличия опытных значений от контроля проанализированы B тесте ANOVA.

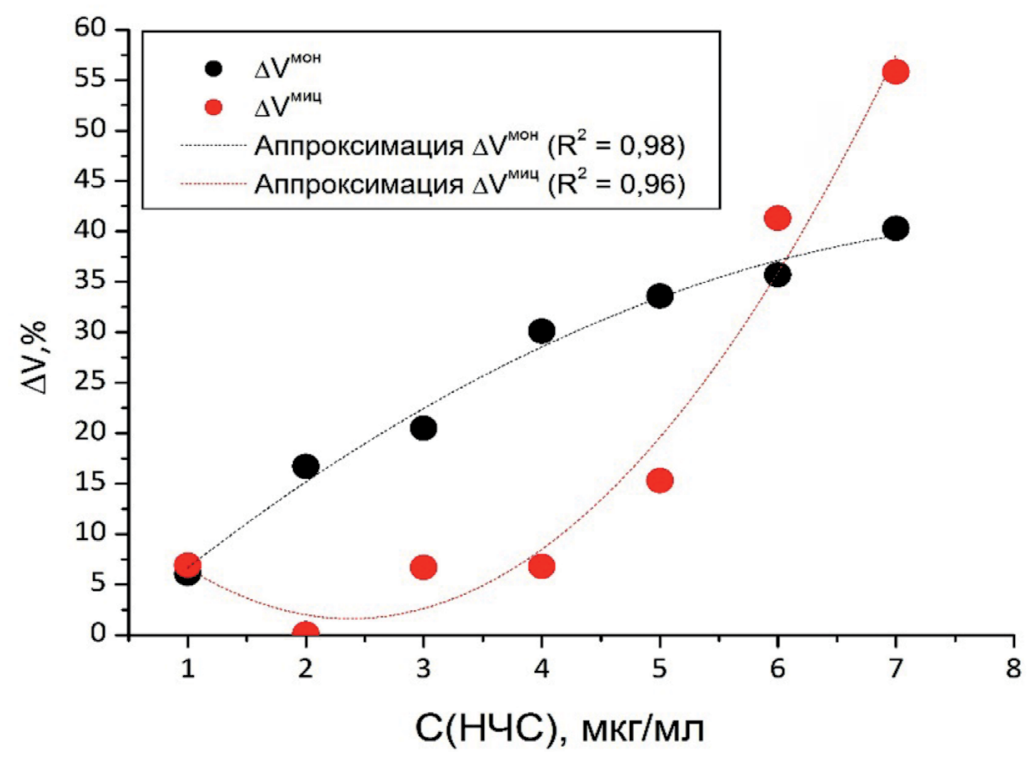

Рис. 2. Вклады мономеров и мицелл в токсический эффект АОТ для клеток ЕА.hy926 при разных концентрациях НЧС. Сокращения: С(НЧС) - соответствующая концентрация наночастиц, $\Delta V$ - общий вклад АОТ в цитотоксичность наночастиц при стандартных разведениях; $\Delta V$ миц и $\Delta \mathrm{V}^{\text {мон }}$ - соответственно, вклад мицелл и мономеров. 
Зависимости вкладов мономеров и мицелл в общую токсичность АОТ в исследованном диапазоне концентраций АОТ и НЧС, найденные по данным рис. 1, показаны на рис. 2.

Видно, что изменения жизнеспособности клеток под действием мономеров и мицелл имеют разный вид, что указывает на возможное различие в механизме их взаимодействия с клетками. Точнее говоря, эти два набора экспериментальных точек аппроксимируются экспонентами, причем в случае мицелл экспонента имеет явную тенденцию к резкому подъему в области высоких концентраций АОТ, тогда как в случае мономеров в той же области наблюдается постепенное увеличение значений $\Delta \mathrm{V}^{\text {мон }}$ и экспонента становиться более пологой. Такие же особенности отмечались нами ранее для зависимостей вкладов мономеров и мицелл, найденных для клеток Jurkat [11]. По нашему мнению, этот результат можно рассматривать как указание на подобие различий в механизме действия этих двух форм ПАВ на клетки разного типа.

\section{Заключение}

Исследование действия стабилизатора наночастиц (АОТ) на жизнеспособность клеток эндотелия (линия ЕА.hу926) показало, что предложенная нами методика исследования механизма токсического действия ПАВ, используемого в качестве стабилизатора наночастиц, на культивируемые клетки разного типа, позволяет выявить отдельные вклады разных форм существования ПАВ в водном растворе и тем самым расширить набор факторов, которые следует учитывать в исследованиях механизма цитотоксичности растворов наночастиц. Используя результаты наших измерений жизнеспособности клеток с помощью МТТ-теста, оказалось возможным оценить токсический эффект только мономеров (молекул) анионного ПАВ и затем найти отдельный вклад мицелл путем вычитания вклада мономеров из общего снижения жизнеспособности, вызванного этим ПАВ. Сравнение соотношения вкладов двух форм при изменении общей концентрации ПАВ показало, что эффекты этих форм имеют характерные отличия, что указывает на возможные различия в механизме цитотоксического действия мономеров и мицелл.

\section{Список литературы}

1. Zhang Y., Li X., Yu H. Toxicity of nanoparticle surface coating agents: Structure-cytotoxicity relationship. J. Environ. Sci. Health C Environ. Carcinog. Ecotoxicol. Rev. 2016; 34(3): 204-215. DOI:10.10 80/10590501.2016.1202762

2. Lu W., Senapati D., Wang S., Tovmachenko O., Singh A.K., Yu H., Ray P.C. Effect of surface coating on the toxicity of silver nanomaterials on human skin keratinocytes. Chem. Phys. Lett. 2010; 487(1-3): 92-96. DOI: 10.1016/j.cplett.2010.01.027

3. Zhang Y., Newton B., Lewis E., Fu P.P., Kafoury R., Ray P.C., $\mathrm{Yu} \mathrm{H}$. Cytotoxicity of organic surface coating agents used for nanoparticles synthesis and stability. Toxicol. In Vitro. 2015; 29(4):
762-768. DOI:10.1016/j.tiv.2015.01.017

4. Brkić Ahmed L., Milić M., Pongrac I.M., Marjanović A.M., Mlinarić H., Pavičić I., Gajović S., Vinković Vrček I. Impact of surface functionalization on the uptake mechanism and toxicity effects of silver nanoparticles in HepG2 cells. Food Chem. Toxicol. 2017; 107(Pt A): 349-361. DOI:10.1016/j.fct.2017.07.016

5. Kaba S.I., Egorova E.M. In vitro studies of the toxic effects of silver nanoparticles on HeLa and U937 cells. Nanotechnol. Sci. Appl. 2015; 8: 19-29. DOI: 10.2147 /NSA.S78134

6. Egorova E.M., Kaba S.I., Tlupova S.A. Assessment of the Cytotoxicity of Silver Nanoparticles with Different Surface Charge. In: $A d-$ vances in Nanotechnology. Eds.: Z. Bartul, J. Trenor. New York: Nova Science Publishers, 2016. 25-48.

7. Каба С.И., Соколовская А.А., Тлупова 3.А., Егорова Е.М. Цитотоксическое действие наночастиц серебра с различным поверхностным зарядом по отношению к клеткам линии Jurkat. Патогенез. 2016; 14(3): 31-37.

8. Егорова Е.М., Каба С.И. Коррекция контроля токсичности стабилизатора в исследовании действия наночастиц серебра на клетки Jurkat. Патологическая физиология и экспериментальная терапия. 2018; 4(62): 269-272. DOI: 10.25557/00312991.2018.04.269-272

9. Inácio Â.S., Mesquita K.A., Baptista M., Ramalho-Santos J., Vaz W.L.C., Vieira O.V. In vitro surfactant structure-toxicity relationships: Implications for surfactant use in sexually transmitted infection prophylaxis and contraception. PLoS One. 2011; 6(5): e19850. DOI:10.1371/journal.pone.0019850

10. Tanford, C. The hydrophobic effect. Formation of micelles and biological membranes (2nd ed.). New York: Wiley, 1980. 232 pp.

11. Egorova E.M., Kaba S.I. The effect of surfactant micellization on the cytotoxicity of silver nanoparticles stabilized with aerosol-OT. Toxicol. In Vitro. 2019; 57: 244-254. DOI: 10.1016/j.tiv.2019.03.006

\section{References}

1. Zhang Y., Li X., Yu H. Toxicity of nanoparticle surface coating agents: Structure-cytotoxicity relationship. J. Environ. Sci. Health C Environ. Carcinog. Ecotoxicol. Rev. 2016; 34(3): 204-215. DOI:10.10 80/10590501.2016.1202762

2. Lu W., Senapati D., Wang S., Tovmachenko O., Singh A.K., Yu H., Ray P.C. Effect of surface coating on the toxicity of silver nanomaterials on human skin keratinocytes. Chem. Phys. Lett. 2010; 487(1-3): 92-96. DOI: 10.1016/j.cplett.2010.01.027

3. Zhang Y., Newton B., Lewis E., Fu P.P., Kafoury R., Ray P.C., $\mathrm{Yu} \mathrm{H}$. Cytotoxicity of organic surface coating agents used for nanoparticles synthesis and stability. Toxicol. In Vitro. 2015; 29(4): 762-768. DOI:10.1016/j.tiv.2015.01.017

4. Brkić Ahmed L., Milić M., Pongrac I.M., Marjanović A.M., Mlinarić H., Pavičić I., Gajović S., Vinković Vrček I. Impact of surface functionalization on the uptake mechanism and toxicity effects of silver nanoparticles in HepG2 cells. Food Chem. Toxicol. 2017; 107(Pt A): 349-361. DOI:10.1016/j.fct.2017.07.016

5. Kaba S.I., Egorova E.M. In vitro studies of the toxic effects of silver nanoparticles on HeLa and U937 cells. Nanotechnol. Sci. Appl. 2015; 8: 19-29. DOI: $10.2147 /$ NSA.S78134

6. Egorova E.M., Kaba S.I., Tlupova S.A. Assessment of the Cytotoxicity of Silver Nanoparticles with Different Surface Charge. In: Advances in Nanotechnology. Eds.: Z.Bartul, J.Trenor. New York: Nova Science Publishers, 2016: 25-48.

7. Kaba S.I., Sokolovskaya A.A., Tlupova Z.A., Egorova E.M. [The cytotoxic effects of silver nanoparticles with different surface charge in Jurkat cells]. Patogenez [Pathogenesis]. 2016; 14(3): 31-37. (in Russian)

8. Egorova E.M., Kaba S.I. [Correction of the toxicity control for stabilizer in studies of the silver nanoparticle effect on Junkat cells]. Patologicheskaya Fiziologiya I Eksperimental'naya Terapiya. [Pathological physiology and experimental therapy]. 2018; 4(62): 269272. DOI: $10.25557 / 0031-2991.2018 .04 .269-272$

9. Inácio Â.S., Mesquita K.A., Baptista M., Ramalho-Santos J., Vaz W.L.C., Vieira O.V. In vitro surfactant structure-toxicity relationships: Implications for surfactant use in sexually transmitted infec- 
tion prophylaxis and contraception. PLoS One. 2011; 6(5): e19850. DOI:10.1371/journal.pone.0019850

10. Tanford, C. The hydrophobic effect. Formation of micelles and biological membranes (2nd ed.). New York: Wiley, 1980. 232 pp.
11. Egorova E.M., Kaba S.I. The effect of surfactant micellization on the cytotoxicity of silver nanoparticles stabilized with aerosol-OT. Toxicol. In Vitro. 2019; 57: 244-254. DOI: 10.1016/j. tiv.2019.03.006

\section{Сведения об авторах:}

Каба Саид Ибрагимович - научный сотрудник лаборатории нанопатологии и биомедицинских нанотехнологий Федерального государственного бюджетного научного учреждения «Научно-исследовательский институт общей патологии и патофизиологии»; https://orcid.org/0000-0001-5391-6707

Егорова Елена Михайловна - доктор химических наук, главный научный сотрудник лаборатории нанопатологии и биомедицинских нанотехнологий Федерального государственного бюджетного научного учреждения «Научно-исследовательский институт общей патологии и патофизиологии» 